\title{
Establishment of EMab-134, a Sensitive and Specific Anti-Epidermal Growth Factor Receptor Monoclonal Antibody for Detecting Squamous Cell Carcinoma Cells of the Oral Cavity
}

\author{
Shunsuke Itai,, ${ }^{1,2}$ Shinji Yamada, Mika K. Kaneko,, Yao-Wen Chang, ${ }_{1}^{1}$ Hiroyuki Harada, and Yukinari Kato ${ }^{1,3}$
}

Epidermal growth factor receptor (EGFR), a receptor tyrosine kinase, activates downstream signaling cascades in many tumors. In this study, we established novel anti-EGFR monoclonal antibodies (mAbs) and characterized their efficacy in flow cytometry, Western blot, and immunohistochemical analyses. We immunized mice with a combination of the extracellular domain of EGFR and EGFR-overexpressing LN229 glioblastoma cells (LN229/ EGFR) and performed the first screening using enzyme-linked immunosorbent assay. Next, we selected mAbs using flow cytometry. Among 156 established clones, two mAbs, EMab-51 ( $\operatorname{IgG}_{1}$, kappa) and EMab-134 (IgG ${ }_{1}$, kappa), reacted with EGFR in Western blot analysis; EMab-134 showed a much higher sensitivity compared with EMab-51. We compared the binding affinities of EMab-51 and EMab-134 using flow cytometry; the calculated $K_{\mathrm{D}}$ values for EMab-51 and EMab-134 against SAS cells/HSC-2 cells were $9.2 \times 10^{-9} \mathrm{M} / 9.9 \times 10^{-9} \mathrm{M}$ and $2.6 \times 10^{-9} \mathrm{M} / 8.3 \times 10^{-9} \mathrm{M}$, respectively, indicating that EMab-134 has a higher affinity to EGFR-expressing cells. Immunohistochemical analysis of EMab-51 and EMab-134 showed sensitive and specific reactions against oral cancer cells; EMab-134 demonstrated a much higher sensitivity (36/38 cases; $94.7 \%$ ) to oral squamous cell carcinomas compared with EMab-51 (6/38 cases; 15.8\%). This novel anti-EGFR mAb, EMab134, could be advantageous for detecting EGFR in the pathological analysis of EGFR-expressing cancers.

Keywords: EGFR, monoclonal antibody, immunohistochemistry, oral cancer

\section{Introduction}

$\mathbf{E}$ PIDERMAL GROWTH FACTOR RECEPTOR (EGFR) is a member of the human EGFR (HER) family of receptor tyrosine kinases. ${ }^{(1-3)}$ EGFR forms homodimers or heterodimers with other members of the HER family, such as HER2 ${ }^{(4)}$ and HER $3,{ }^{(5)}$ controlling many biological processes. EGFR is a type-I transmembrane glycoprotein that is involved in cell growth and differentiation. ${ }^{(6)}$ Overexpression of EGFR is observed in many cancers, including head and neck, lung, colorectal, breast, pancreatic, kidney, ovary, bladder, and prostate cancers. ${ }^{(7)}$

Monoclonal antibodies (mAbs) have been developed for cancer treatment, including cetuximab (a mouse-human chimeric $\mathrm{mAb} ; \mathrm{IgG}_{1}$ ) against head and neck and colorectal cancers, panitumumab (a fully human $\mathrm{mAb} ; \mathrm{IgG}_{2}$ ) against colorectal cancers, and necitumumab (a fully human $\mathrm{mAb} ; \mathrm{IgG}_{1}$ ) against non-small cell lung cancers. ${ }^{(8-10)}$ Anti-EGFR mAbs possess various functional mechanisms: antibody-dependent cellular cytotoxicity (ADCC), complement-dependent cytotoxicity (CDC), blocking dimerization, blocking ligand binding, and EGFR endocytosis.

Recently, we developed anti-HER2 mAb (clone: $\mathrm{H}_{2} \mathrm{Mab}-$ 77) using our original technology. $\mathrm{H}_{2} \mathrm{Mab}-77$ is useful for Western blot, flow cytometry, and immunohistochemical analyses. $^{(11)}$ In this study, we established sensitive and specific $m$ Abs against EGFR.

\section{Materials and Methods}

\section{Cell lines}

Chinese hamster ovary (CHO)-K1, P3X63Ag8U.1 (P3U1), HEK-293T, Met-5A, LN229, and A431 were obtained from the American Type Culture Collection (ATCC; Manassas, VA). HSC-2, HSC-3, HSC-4, HSC-3M3, Ca9-22, HO-1-u-1, and SAS were obtained from the Japanese Collection of Research

\footnotetext{
${ }^{1}$ Department of Antibody Drug Development, Tohoku University Graduate School of Medicine, Sendai, Japan.

${ }^{2}$ Department of Oral and Maxillofacial Surgery, Graduate School of Medical and Dental Sciences, Tokyo Medical and Dental University, Tokyo, Japan.

${ }^{3}$ New Industry Creation Hatchery Center, Tohoku University, Sendai, Japan.

(C) Shunsuke Itai et al. 2017; Published by Mary Ann Liebert, Inc. This Open Access article is distributed under the terms of the Creative Commons License (http://creativecommons.org/licenses/by/4.0), which permits unrestricted use, distribution, and reproduction in any medium, provided the original work is properly cited.
} 
Bioresources Cell Bank (Osaka, Japan). LN229/EGFR and CHO/EGFR were produced by transfecting pCAG/PAEGFR-RAP-MAP into LN229 and CHO-K1 cells using the Neon transfection system (Thermo Fisher Scientific, Inc., Waltham, MA) and Lipofectamine LTX (Thermo Fisher Scientific, Inc.), respectively. ${ }^{(12)}$ A few days after transfection, PA tag-positive cells were sorted using a cell sorter (SH800; Sony Corp., Tokyo, Japan). The PA tag system comprises a rat anti-human podoplanin mAb (clone NZ-1) and the PA tag (GVAMPGAEDDVV) derived from the platelet aggregation-stimulating (PLAG) domain of human podoplanin. ${ }^{(13)}$

\section{Animals and tissues}

Four-week-old female BALB/c mice were purchased from CLEA Japan (Tokyo, Japan). Animals were housed under specific pathogen-free conditions. The Animal Care and Use Committee of Tohoku University approved all of the animal experiments described. Oral cancer tissue arrays were purchased from US Biomax, Inc. (Rockville, MD).

\section{Culture of cell lines}

CHO-K1, CHO/EGFR, and P3U1 cell lines were cultured in RPMI 1640 medium (Nacalai Tesque, Inc., Kyoto, Japan), and LN229, LN229/EGFR, A431, HSC-2, HSC-3, HSC-4, HSC3M3, Ca9-22, HO-1-u-1, SAS, HEK-293T, and Met-5A cell lines were cultured in Dulbecco's modified Eagle's medium (DMEM) (Nacalai Tesque, Inc.), supplemented with 10\% heat-inactivated fetal bovine serum (Thermo Fisher Scientific, Inc.), $100 \mathrm{U} / \mathrm{mL}$ of penicillin, $100 \mu \mathrm{g} / \mathrm{mL}$ of streptomycin, and $25 \mu \mathrm{g} / \mathrm{mL}$ of amphotericin B (Nacalai Tesque, Inc.) at $37^{\circ} \mathrm{C}$ in a humidified atmosphere containing $5 \% \mathrm{CO}_{2}$ and $95 \%$ air.
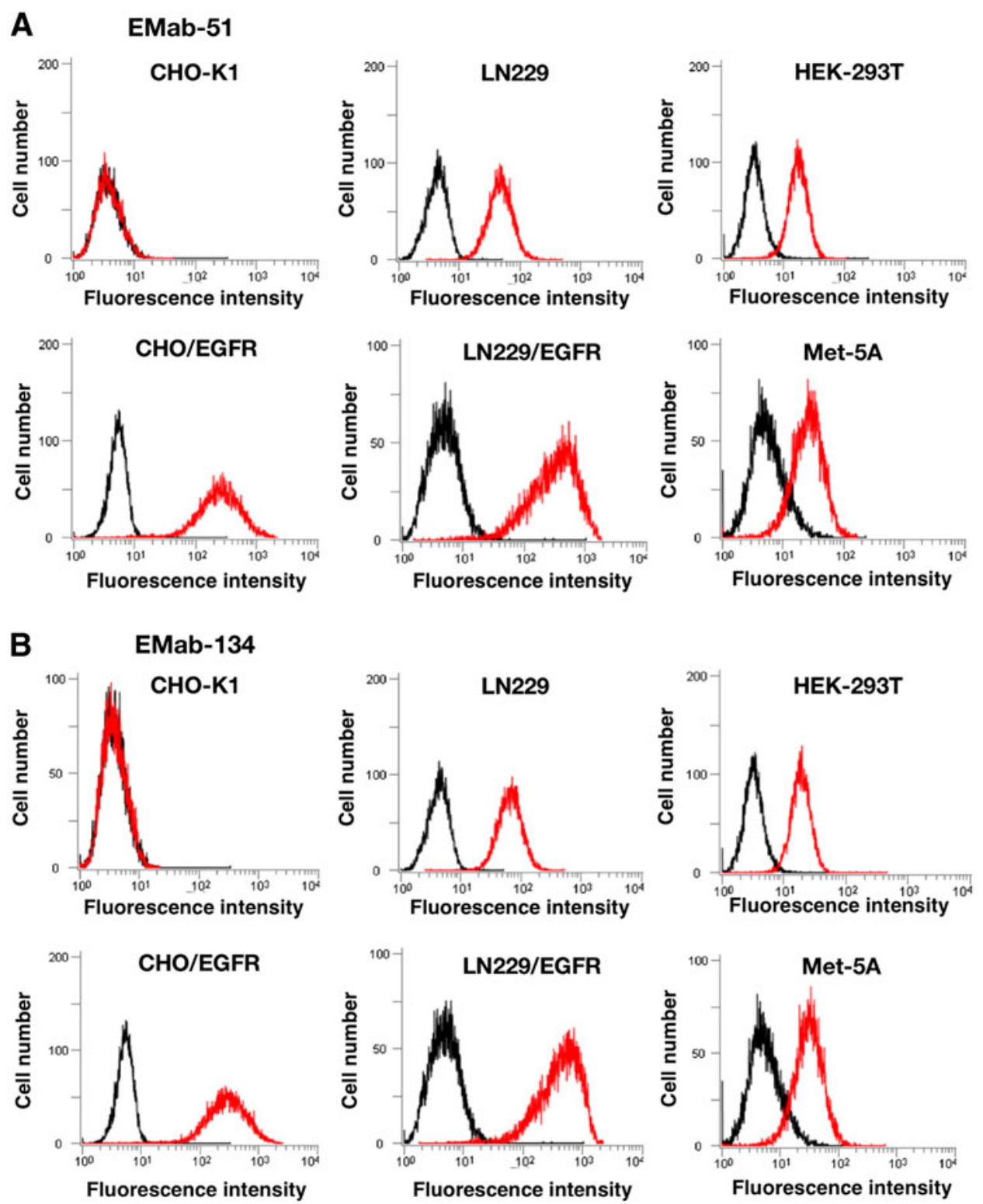

FIG. 1. Flow cytometry using anti-EGFR mAbs for several cells. Cells were treated with $1 \mu \mathrm{g} / \mathrm{mL}$ of EMab-51 (A) and EMab-134 (B), followed by treatment with Alexa Fluor 488-conjugated anti-mouse IgG; black line, negative control. EGFR, epidermal growth factor receptor; mAbs, monoclonal antibodies. 


\section{Purification of extracellular domain of EGFR}

The extracellular domain of EGFR with N-terminal PA tag and C-terminal RAP tag-MAP tag was purified from the supernatant of LN229/sol-EGFR using anti-RAP tag, as described previously. ${ }^{(14)}$ The RAP tag system comprises a mouse anti-rat podoplanin mAb (clone PMab-2) and the RAP tag (DMVNPGLEDRIE) derived from the PLAG domain of rat podoplanin. ${ }^{(14)}$

\section{Production of hybridoma cell lines}

$\mathrm{BALB} / \mathrm{c}$ mice were immunized using intraperitoneal injections of LN229/EGFR cells or $100 \mu \mathrm{g}$ of sol-EGFR together with Imject Alum (Thermo Fisher Scientific, Inc.). After several additional immunizations, a booster injection of LN229/EGFR cells or $100 \mu \mathrm{g}$ of sol-EGFR was intraperitoneally administered 2 days before harvesting spleen cells. Spleen cells were then fused with P3U1 cells using PEG1500 (Roche Diagnostics, Indianapolis, IN) or GenomONE-CF (Ishihara Sangyo Kaisha, Ltd., Osaka, Japan). The resulting hybridomas were grown in RPMI 1640 medium supplemented with hypoxanthine, aminopterin, and thymidine selection medium supplement (Thermo Fisher Scientific,
Inc.). Culture supernatants were screened using enzymelinked immunosorbent assay (ELISA) with sol-EGFR, and mAbs were selected using flow cytometry, Western blot, and immunohistochemical analyses.

\section{Purification of $m A b s$}

Hybridomas were cultured in Hybridoma-SFM medium (Thermo Fisher Scientific, Inc.). mAbs were purified from supernatants using Protein G Sepharose 4 Fast Flow (GE Healthcare UK Ltd., Buckinghamshire, England).

\section{Flow cytometry}

Cells were harvested by brief exposure to $0.25 \%$ trypsin/ 1-mM ethylenediaminetetraacetic acid (EDTA) (Nacalai Tesque, Inc.). After washing with $0.1 \%$ bovine serum albumin (BSA)/phosphate buffered saline (PBS), the cells were treated with $1 \mu \mathrm{g} / \mathrm{mL}$ of anti-EGFR for 30 minutes at $4^{\circ} \mathrm{C}$, followed by treatment with Alexa Fluor 488-conjugated anti-mouse IgG (1:1000; Cell Signaling Technology, Inc., Danvers, MA). Fluorescence data were collected using EC800 Cell Analyzers (Sony Corp.).
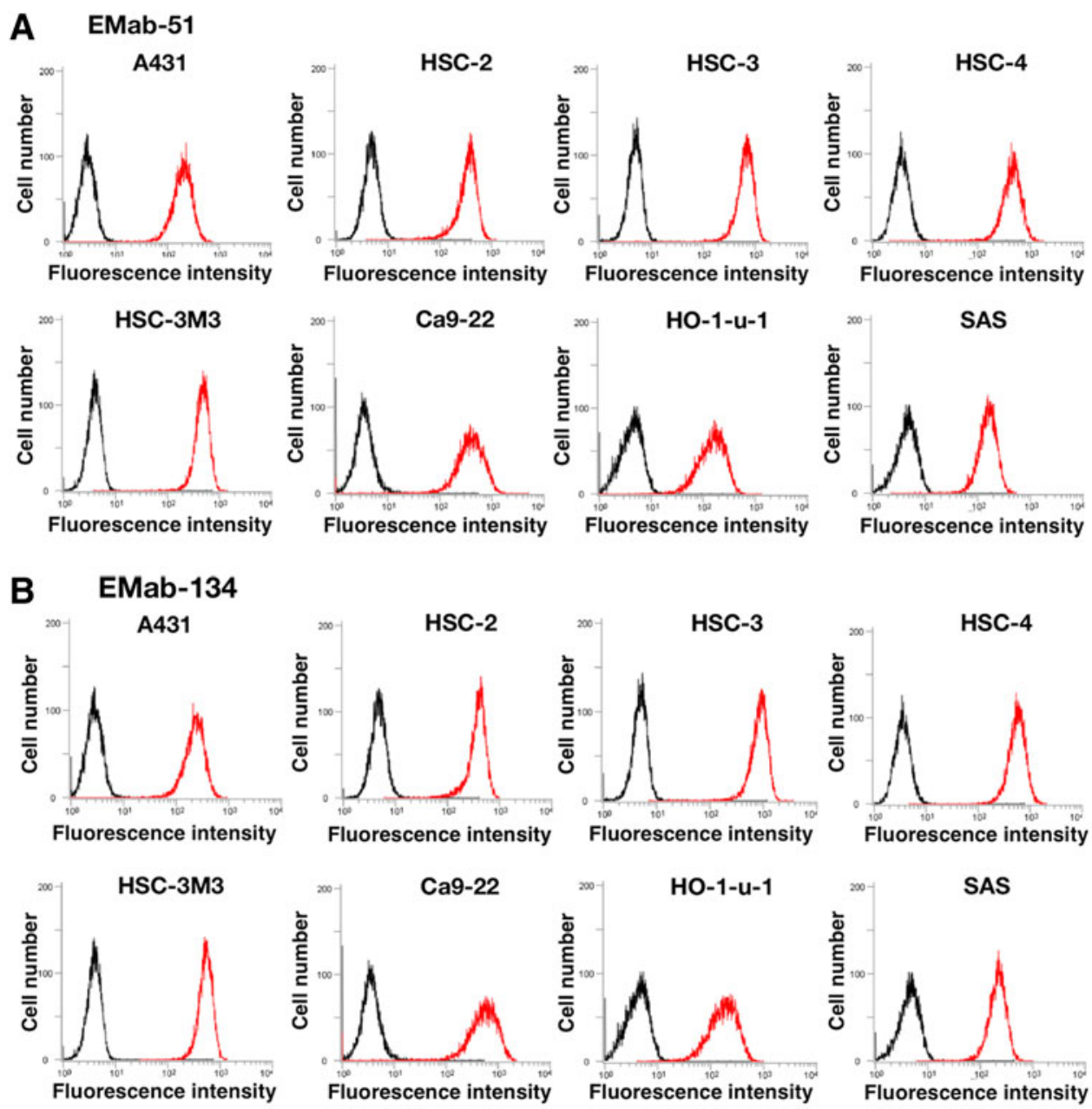

FIG. 2. Flow cytometry using anti-EGFR mAbs for squamous cell carcinoma cell lines. Cells were treated with $1 \mu \mathrm{g} / \mathrm{mL}$ of EMab-51 (A) and EMab-134 (B), followed by treatment with Alexa Fluor 488-conjugated anti-mouse IgG; black line, negative control. 


\section{Determination of the binding} affinity using flow cytometry

SAS and HSC-2 $\left(2 \times 10^{5}\right.$ cells $)$ were suspended in $100 \mu \mathrm{L}$ of serially diluted mAbs $(0.6 \mathrm{ng} / \mathrm{mL}-10 \mu \mathrm{g} / \mathrm{mL})$, and Alexa Fluor 488-conjugated anti-mouse IgG (1:1000; Cell Signaling Technology, Inc.) was then added. Fluorescence data were collected using a cell analyzer (EC800; Sony Corp.). The dissociation constant $\left(K_{\mathrm{D}}\right)$ was calculated by fitting the binding isotherms using the built-in one-site binding models in GraphPad PRISM 6 (GraphPad Software, Inc., La Jolla, CA).

\section{Western blot analysis}

Cell lysates $(10 \mu \mathrm{g})$ were boiled in SDS sample buffer (Nacalai Tesque, Inc.). Proteins were then electrophoresed on 5\%-20\% polyacrylamide gels (Wako Pure Chemical Industries Ltd., Osaka, Japan) and transferred onto polyvinylidene difluoride (PVDF) membranes (Merck KGaA, Darmstadt, Germany). After blocking with 4\% skim milk (Nacalai Tesque, Inc.), membranes were incubated with antiEGFR $(1-10 \mu \mathrm{g} / \mathrm{mL})$ and $1 \mu \mathrm{g} / \mathrm{mL}$ of anti- $\beta$-actin (clone AC-15; Sigma-Aldrich Corp., St. Louis, MO), followed by incubation with peroxidase-conjugated anti-mouse IgG (diluted 1:1000; Agilent Technologies, Inc., Santa Clara,
CA), and were finally developed using ImmunoStar LD (Wako Pure Chemical Industries Ltd.) using a Sayaca-Imager (DRC Co. Ltd., Tokyo, Japan).

\section{Immunohistochemical analyses}

Histological sections (4- $\mu \mathrm{m}$ thick) were directly autoclaved in EnVision FLEX Target Retrieval Solution High $\mathrm{pH}$ (Agilent Technologies, Inc.) for 20 minutes or were deparaffinized in xylene and then rehydrated and autoclaved in citrate buffer, $\mathrm{pH} 6.0$ (Agilent Technologies, Inc.) for 20 minutes. Sections were then incubated with $5 \mu \mathrm{g} / \mathrm{mL}$ of mAbs for 1 hour at room temperature, followed by treatment with an Envision+ kit (Agilent Technologies, Inc.) for 30 minutes. Color was developed using 3,3-diaminobenzidine tetrahydrochloride (Agilent Technologies, Inc.) for 2 minutes, and sections were then counterstained with hematoxylin (Wako Pure Chemical Industries Ltd.). The intensity of staining was evaluated as $0,1+, 2+$, or $3+$.

\section{Results}

\section{Establishment of anti-EGFR mAbs}

EGFR is a type-I transmembrane glycoprotein, which is similar to the platelet aggregation-inducing factor
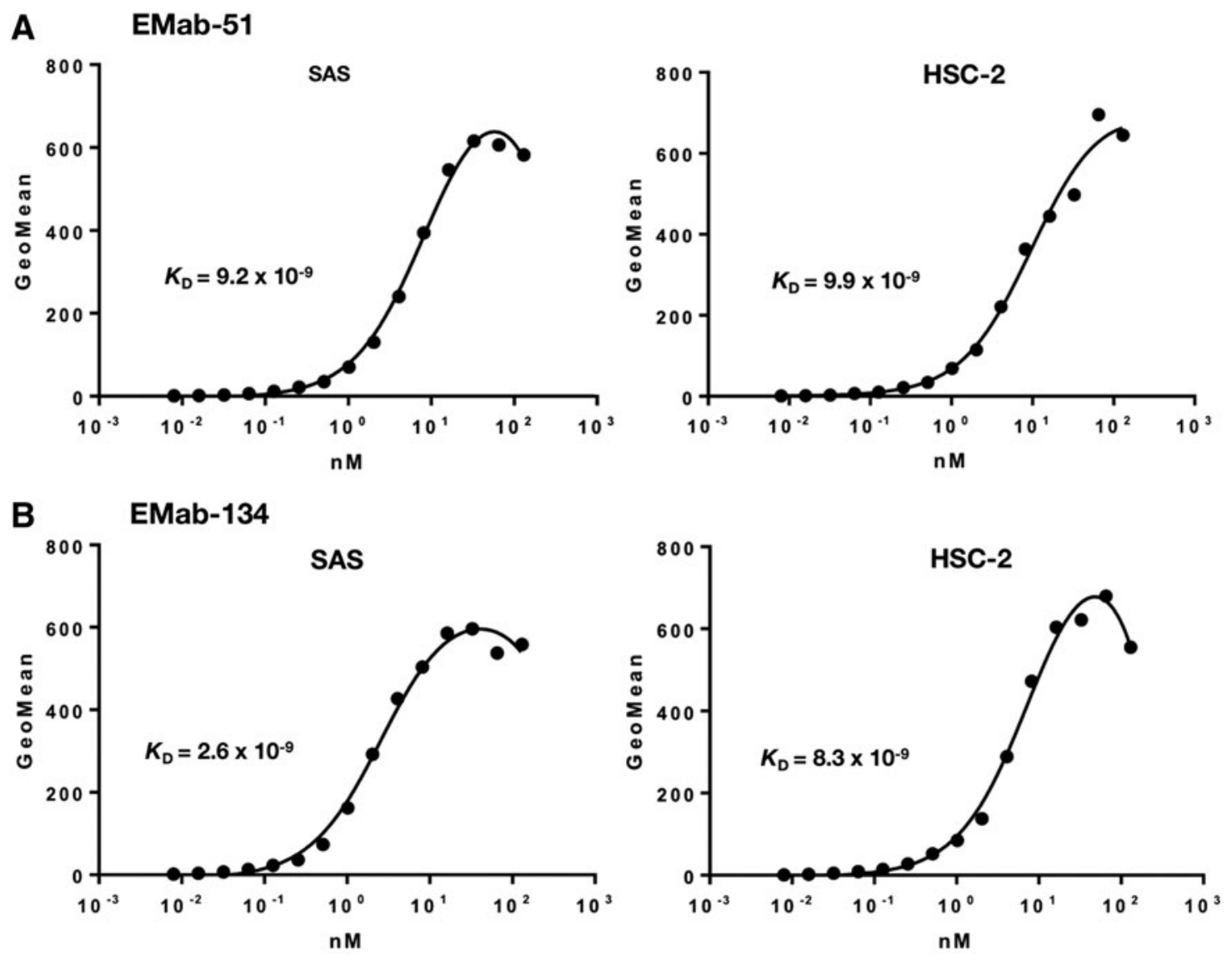

FIG. 3. Determination of binding affinity using flow cytometry. SAS and HSC-2 were suspended in $100 \mu \mathrm{L}$ of serially diluted EMab-51 (A) or EMab-134 (B) $(0.6 \mathrm{ng} / \mathrm{mL}-10 \mu \mathrm{g} / \mathrm{mL})$, and secondary anti-mouse IgG was then added. Fluorescence data were collected using a cell analyzer. 
podoplanin. ${ }^{(15)}$ We previously produced anti-podoplanin cancer-specific mAbs (CasMabs), clones LpMab-2 ${ }^{(16,17)}$ and LpMab-23, ${ }^{(18,19)}$ which particularly recognized cancer-type podoplanin. It is critical that immunogens are produced using cancer cell lines, such as LN229 glioblastoma cells, which express cancer-specific glycan-attached membrane proteins. We have used this method to develop useful mAbs against many membrane proteins. ${ }^{(20)}$

In this study, we immunized mice with LN229/EGFR or purified recombinant EGFR (sol-EGFR). Culture supernatants were then screened for binding to sol-EGFR using ELISA. We then used flow cytometry as a second screen to assess reactions with LN229 and LN229/EGFR cells. A stronger reaction against LN229/EGFR was required because LN229 cells express endogenous EGFR. ${ }^{(21)}$ Of 156 established clones, only two mAbs (1.3\%), EMab$51\left(\mathrm{IgG}_{1}\right.$, kappa) and EMab-134 (IgG 1 , kappa), reacted with EGFR in Western blot analysis. Both mAbs were produced by immunizing sol-EGFR. We purified EMab51 and EMab-134 using Protein G and characterized these mAbs.

\section{Characterization of anti-EGFR mAbs}

In flow cytometry, EMab-51 reacted with CHO/EGFR but not with the parental cell CHO-K1, indicating that EMab-51 had specificity for EGFR (Fig. 1A). EMab-51 also reacted with LN229/EGFR more strongly than with endogenous EGFR-expressing LN229 glioblastoma cells (Fig. 1A). Moreover, EMab-51 reacted with normal cell lines, including HEK-293T (renal epithelial cells) and Met-5A (mesothelial cells). ${ }^{(22)}$ The reactions of EMab-134 were very similar to those of EMab-51 (Fig. 1B).

EMab-51 recognized endogenous EGFR in A431 epidermoid carcinoma cells ${ }^{(23)}$ (Fig. 2A). EMab-51 also reacted with oral squamous cell carcinomas such as HSC-2, HSC-3, HSC-4, HSC-3M3, Ca9-22, HO-1-u-1, and SAS, indicating that EMab-51 detected each squamous cell carcinoma cell line at a low concentration $(1 \mu \mathrm{g} / \mathrm{mL})$ in flow cytometry. Another clone, EMab-134, also reacted with squamous cell carcinoma cell lines in the same way as EMab51 (Fig. 2B).

We further determined the binding affinities of EMab51 and EMab-134 for SAS and HSC-2 cells through flow cytometry (Fig. 3) and calculated $K_{\mathrm{D}}$ values for EMab-51 and EMab-134. $K_{\mathrm{D}}$ values of EMab-51 were determined to be $9.2 \times 10^{-9} \mathrm{M}$ and $9.9 \times 10^{-9} \mathrm{M}$ against SAS and HSC-2, respectively. In contrast, $K_{\mathrm{D}}$ values of EMab-134 were determined to be $2.6 \times 10^{-9} \mathrm{M}$ and $8.3 \times 10^{-9} \mathrm{M}$ against SAS and HSC-2, respectively, indicating that the binding affinities of EMab-134 were 3.5 times and 1.2 times higher than those of EMab-51 against SAS and HSC-2, respectively.

Next, we compared the reactivity between EMab-51 and EMab-134 in Western blot analysis. As shown in Figure 4, both EMab-51 and EMab-134 reacted with LN229/EGFR. However, the sensitivity of EMab-134 was much higher compared with EMab-51, although their reactivity was similar in flow cytometry (Figs. 1 and 2). Both mAbs reacted with endogenous EGFR, which was reported to be expressed in A431 cells. ${ }^{(23)}$ EMab-51 detected an $\sim 180-\mathrm{kDa}$ weak signal in LN229/EGFR and a strong signal in A431 cells
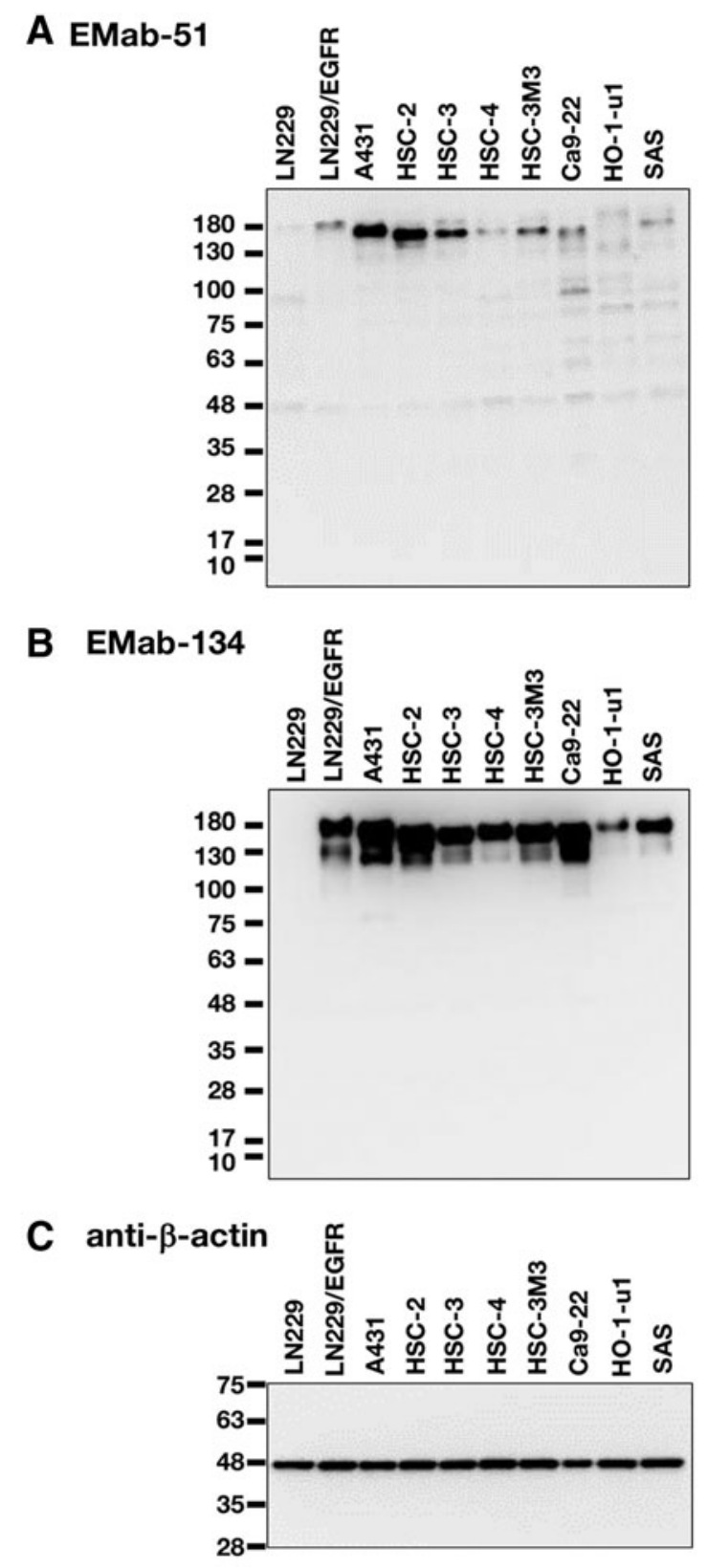

FIG. 4. Western blot analysis using EMab-51 and EMab134. Cell lysates $(10 \mu \mathrm{g})$ were electrophoresed, and proteins were transferred onto PVDF membranes. After blocking, membranes were incubated with $10 \mu \mathrm{g} / \mathrm{mL}$ of EMab-51 (A), $1 \mu \mathrm{g} / \mathrm{mL}$ of EMab-134 (B), or $1 \mu \mathrm{g} / \mathrm{mL}$ of anti- $\beta$-actin (clone: $\mathrm{AC}$-15) (C) and then incubated with peroxidaseconjugated anti-mouse IgG. PVDF, polyvinylidene difluoride.

(Fig. 4A), whereas EMab-134 detected 180- and 130-kDa signals in LN229/EGFR and A431 cells, respectively (Fig. 4B). Furthermore, EMab-134 showed strong signals against five human oral cancer cell lines (HSC-2, HSC-3, HSC-4, HSC3M3, and Ca9-22) and moderate signals against two human oral cancer cell lines (HO-1-u-1 and SAS; Fig. 4B), which were compatible with the flow cytometric data (Fig. 3). In contrast, EMab-51 showed moderate signals against two cell lines 
(HSC-2 and HSC-3) and weak signals against the other cell lines (Fig. 4A).

\section{Immunohistochemical analysis for oral cancers}

We performed immunohistochemical analysis using EMab-134 for human oral cancers because EGFR expression was highly observed in oral cancer cell lines (Fig. 2). First, we investigated the antigen retrieval conditions for immunohistochemical analysis using EMab-134. EMab-134 stained the membranes of cancer cells of oral squamous cell carcinomas (Fig. 5A-D). The sensitivity using EnVision FLEX Target Retrieval Solution High pH (Fig. 5A, B and Supplementary Fig. S1A, B) was much higher than that using citrate buffer $(\mathrm{pH}$ 6.0) as the antigen retrieval solution (Fig. 5C, D and Supplementary Fig. S1C, D). Next, we compared the immunoreactivity of EMab-51 and EMab-134 under the same conditions (Fig. 6). EMab-134 (Fig. 6A, B) showed much stronger signals than EMab-51 (Fig. 6C, D), although the staining areas of EMab-134 and EMab-51 were the same. All staining results of EMab-51 and EMab-134 for oral cancers are shown in Table 1. EMab-51 stained 6/38 (15.8\%) of squamous cell carcinomas, whereas EMab-134 stained 36/38 $(94.7 \%)$ of the carcinomas (Table 2). Several typical results of EMab-134 are also shown in Supplementary Figures S2 (intensity: 3+) and S3 (intensity: 2+).

\section{Discussion}

To date, we have developed many mAbs against membrane proteins. We recently developed specific and sensitive antipodocalyxin mAbs using a technology developed by us and demonstrated that the clone PcMab-47 was the most useful for flow cytometry, Western blot, and immunohistochemical analyses among the 100 anti-podocalyxin mAb clones. PcMab-47 has been useful for investigations of podocalyxin
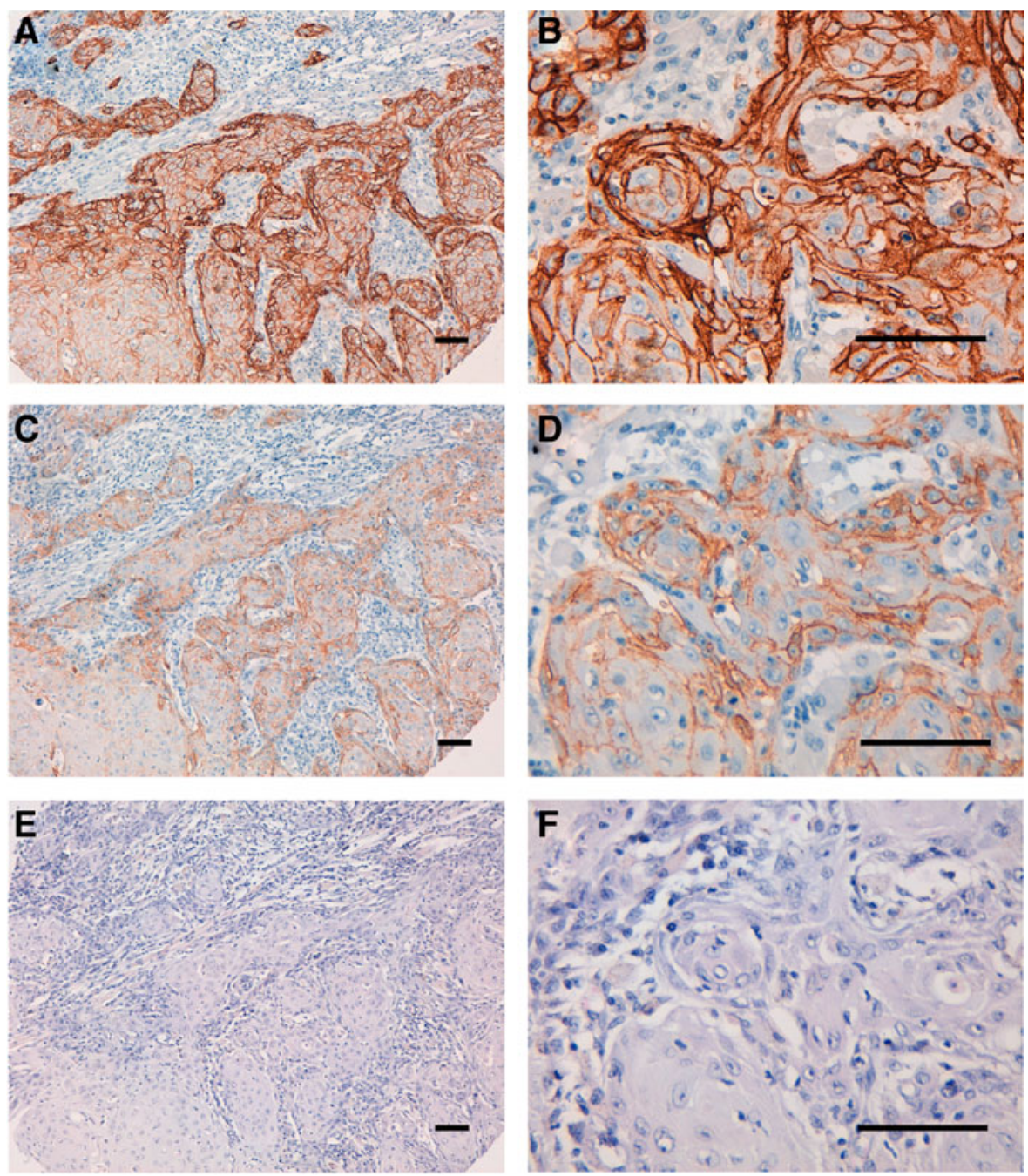

FIG. 5. Immunohistochemical analysis by EMab-134 for oral cancers. After antigen retrieval, sections (Case-24) were incubated with $5 \mu \mathrm{g} / \mathrm{mL}$ of primary EMab-134 for 1 hour at room temperature, followed by treatment with Envision+ kit for 30 minutes. Color was developed using 3,3-diaminobenzidine tetrahydrochloride for 2 minutes, and sections were then counterstained with hematoxylin. (A, B) Antigen retrieval using EnVision FLEX Target Retrieval Solution High pH; (C, D) antigen retrieval using citrate buffer, pH 6.0; (E, F) hematoxylin and eosin staining; scale bar $=100 \mu \mathrm{m}$. 

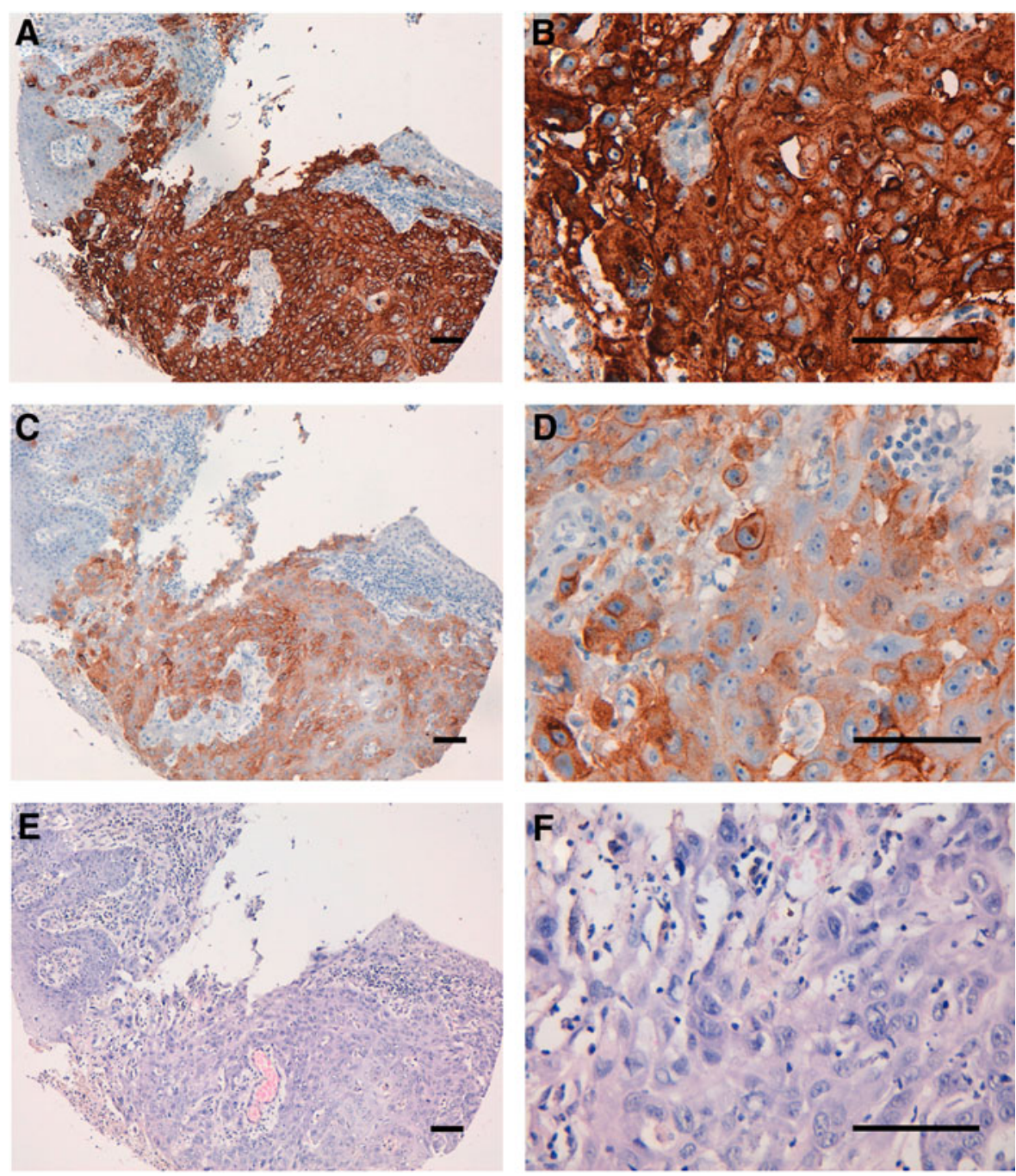

FIG. 6. Immunohistochemical analysis by anti-EGFR mAbs for oral cancers. After antigen retrieval using EnVision FLEX Target Retrieval Solution High $\mathrm{pH}$, sections (Case-15) were incubated with $5 \mu \mathrm{g} / \mathrm{mL}$ of primary EMab-134 or EMab-51 for 1 hour at room temperature, followed by treatment with Envision+ kit for 30 minutes. Color was developed using 3,3-diaminobenzidine tetrahydrochloride for 2 minutes, and sections were then counterstained with hematoxylin. (A, B) EMab-134; (C, D) EMab-51; (E, F) hematoxylin and eosin staining; scale bar $=100 \mu \mathrm{m}$.

expression and function in cancers and normal tissues. ${ }^{(20)} \mathrm{We}$ also used our technology to generate mAbs that bind to various novel epitopes of podoplanin, including LpMab-3, ${ }^{(24)} \mathrm{LpMab}-$ $12,{ }^{(25)}$ LpMab-19, ${ }^{(26)}$ and LpMab-21. ${ }^{(27,28)}$ Importantly, these mAbs are useful for Western blot, flow cytometry, and immunohistochemical analyses for podoplanin. Recently, we further developed anti-HER2 mAb (clone: $\mathrm{H}_{2} \mathrm{Mab}-77$ ), which is also useful for Western blot, flow cytometry, and immunohistochemical analyses. ${ }^{(11)}$ Development of mAbs, which are useful for various experiments, is often difficult because the design of immunogens and screening methods to produce specific mAbs differ based on the applications. Furthermore, it is difficult to produce mAbs sensitive and specific to endogenous proteins.

In this study, we immunized mice with a combination of LN229/EGFR and recombinant EGFR to develop specific and sensitive anti-EGFR mAbs, which were useful for Western blotting, flow cytometry, and immunohistochemical analyses. Two established clones, EMab-51 and EMab-134, were determined to be of the $\operatorname{IgG}_{1}$ subclass, precluding confirmation of $\mathrm{ADCC}$ or $\mathrm{CDC}$ without conversion to mouse $\operatorname{IgG}_{2 \mathrm{a}}$, mouse $\mathrm{IgG}_{2 \mathrm{~b}}$, or human $\mathrm{IgG}_{1}$. In future studies, we will convert the subclass of EMab-51 and EMab-134 into ADCC/CDC-inducing subclasses for measuring ADCC/CDC activities. ${ }^{(17,29,30)}$ Furthermore, we should determine the epitope of EMab-134 and EMab-51 and investigate the reason why EMab-134 is sensitive in Western blot and immunohistochemical analyses.

In conclusion, of 156 clones of anti-EGFR mAbs, EMab134 was highly efficacious in Western blot analysis and strongly stained oral cancers. Thus, EMab-134 could be useful in various experiments and advantageous for the pathological identification of EGFR in many cancers. 
Table 1. Results of EMab-51 and EMab-134 Immunostaining in 48 Patients with Oral Cancers

\begin{tabular}{|c|c|c|c|c|c|c|c|c|}
\hline No. & Sex & Age & Organ & Pathology diagnosis & Differentiation & Type & $E M a b-51$ & EMab-134 \\
\hline 1 & M & 61 & Tongue & $\mathrm{SCC}$ & Well & Malignant & 0 & 0 \\
\hline 2 & $\mathrm{~F}$ & 57 & Tongue & SCC & Well & Malignant & 0 & $1+$ \\
\hline 3 & $\mathrm{~F}$ & 67 & Tongue & $\mathrm{SCC}$ & Well & Malignant & 0 & $2+$ \\
\hline 4 & M & 59 & Tongue & SCC & Well & Malignant & 0 & $1+$ \\
\hline 5 & $\mathrm{~F}$ & 47 & Tongue & SCC & Well & Malignant & 0 & $1+$ \\
\hline 6 & $\mathrm{~F}$ & 62 & Tongue & SCC & - & Malignant & 0 & $3+$ \\
\hline 7 & $\mathrm{~F}$ & 47 & Tongue & $\mathrm{SCC}$ & Well & Malignant & 0 & $2+$ \\
\hline 8 & M & 51 & Tongue & $\mathrm{SCC}$ & Well & Malignant & 0 & 0 \\
\hline 9 & M & 62 & Tongue & $\mathrm{SCC}$ & Well & Malignant & 0 & $2+$ \\
\hline 10 & $\mathrm{~F}$ & 53 & Tongue & $\mathrm{SCC}$ & Well & Malignant & 0 & $3+$ \\
\hline 11 & M & 50 & Tongue & $\mathrm{SCC}$ & Well & Malignant & 0 & $3+$ \\
\hline 12 & M & 76 & Tongue & $\mathrm{SCC}$ & Well & Malignant & 0 & $3+$ \\
\hline 13 & $\mathrm{M}$ & 55 & Tongue & SCC & Well & Malignant & 0 & $1+$ \\
\hline 14 & $\mathrm{~F}$ & 57 & Tongue & $\mathrm{SCC}$ & Moderately & Malignant & 0 & $1+$ \\
\hline 15 & $\mathrm{M}$ & 61 & Tongue & SCC & Well & Malignant & $3+$ & $3+$ \\
\hline 16 & $\mathrm{~F}$ & 50 & Tongue & $\mathrm{SCC}$ & Well & Malignant & 0 & $2+$ \\
\hline 17 & M & 54 & Tongue & $\mathrm{SCC}$ & Well & Malignant & 0 & $2+$ \\
\hline 18 & $\mathrm{M}$ & 62 & Tongue & SCC & Well & Malignant & 0 & $1+$ \\
\hline 19 & $\mathrm{~F}$ & 55 & Tongue & $\mathrm{SCC}$ & Well & Malignant & $2+$ & $3+$ \\
\hline 20 & $\mathrm{~F}$ & 63 & Tongue & $\mathrm{SCC}$ & Well & Malignant & 0 & $1+$ \\
\hline 21 & M & 56 & Tongue & $\mathrm{SCC}$ & Well & Malignant & 0 & $1+$ \\
\hline 22 & $\mathrm{~F}$ & 45 & Tongue & SCC & Well & Malignant & 0 & $3+$ \\
\hline 23 & $\mathrm{M}$ & 50 & Tongue & $\mathrm{SCC}$ & Well & Malignant & $2+$ & $3+$ \\
\hline 24 & $\mathrm{~F}$ & 46 & Tongue & $\mathrm{SCC}$ & Poorly & Malignant & 0 & $3+$ \\
\hline 25 & $\mathrm{~F}$ & 48 & Tongue & SCC & Moderately & Malignant & 0 & $2+$ \\
\hline 26 & $\mathrm{~F}$ & 67 & Tongue & SCC & — & Malignant & 0 & $2+$ \\
\hline 27 & $\mathrm{M}$ & 64 & Tongue & SCC & Poorly & Malignant & $1+$ & $3+$ \\
\hline 28 & $\mathrm{~F}$ & 50 & Tongue & $\mathrm{SCC}$ & Moderately & Malignant & 0 & $1+$ \\
\hline 29 & M & 63 & Tongue & $\mathrm{SCC}$ & Moderately & Malignant & 0 & $2+$ \\
\hline 30 & $\mathrm{~F}$ & 46 & Tongue & SCC & Well & Malignant & 0 & $2+$ \\
\hline 31 & $\mathrm{~F}$ & 35 & Tongue & $\mathrm{SCC}$ & Moderately & Malignant & 0 & $2+$ \\
\hline 32 & M & 55 & Tongue & $\mathrm{SCC}$ & Poorly & Malignant & 0 & $1+$ \\
\hline 33 & $\mathrm{M}$ & 49 & Tongue & $\mathrm{SCC}$ & Poorly & Malignant & 0 & $2+$ \\
\hline 34 & $\mathrm{M}$ & 61 & Tongue & SCC & Moderately & Malignant & 0 & $1+$ \\
\hline 35 & M & 53 & Tongue & $\mathrm{SCC}$ & Moderately & Malignant & $1+$ & $3+$ \\
\hline 36 & $\mathrm{~F}$ & 51 & Tongue & SCC & Poorly & Malignant & 0 & $2+$ \\
\hline 37 & $\mathrm{M}$ & 73 & Tongue & SCC & Poorly & Malignant & 0 & $2+$ \\
\hline 38 & $\mathrm{M}$ & 61 & Tongue & SCC & Poorly & Malignant & $1+$ & $3+$ \\
\hline 39 & $\mathrm{M}$ & 62 & Tongue & $\mathrm{ACC}$ & - & Malignant & 0 & 0 \\
\hline 40 & $\mathrm{M}$ & 50 & Tongue & $\mathrm{MC}$ & - & Malignant & 0 & 0 \\
\hline 41 & M & 68 & Parotid & PA & - & Malignant & 0 & $1+$ \\
\hline 42 & M & 58 & Parotid & PA & - & Malignant & 0 & 0 \\
\hline 43 & $\mathrm{M}$ & 41 & Parotid & PA & - & Malignant & 0 & 0 \\
\hline 44 & $\mathrm{~F}$ & 45 & Parotid & MPA & - & Malignant & 0 & 0 \\
\hline 45 & $\mathrm{M}$ & 57 & Parotid & MPA & - & Malignant & 0 & $1+$ \\
\hline 46 & $\mathrm{M}$ & 52 & Parotid & MPA & - & Malignant & 0 & $1+$ \\
\hline 47 & M & 65 & Parotid & $\mathrm{AL}$ & - & Malignant & 0 & $1+$ \\
\hline 48 & $\mathrm{~F}$ & 74 & Parotid & $\mathrm{ACC}$ & - & Malignant & 0 & $1+$ \\
\hline
\end{tabular}

ACC, adenoid cystic carcinoma; AL, adenolymphoma; F, female; M, male; MC, mucoepidermoid carcinoma; MPA, malignant pleomorphic adenoma; PA, pleomorphic adenoma; SCC, squamous cell carcinoma.

Table 2. Summary of Immunostaining Using EMab-51 and EMab-134

\begin{tabular}{|c|c|c|c|c|c|c|c|c|c|c|c|}
\hline \multirow{2}{*}{$\begin{array}{l}\text { Tumor } \\
\text { type }\end{array}$} & \multirow{2}{*}{$\begin{array}{c}\text { No. of } \\
\text { cases }\end{array}$} & \multicolumn{4}{|c|}{ EMab-51 immunostaining } & \multirow{2}{*}{$\begin{array}{l}\text { No. of positive } \\
\text { cases }(\%)\end{array}$} & \multicolumn{4}{|c|}{ EMab-134 immunostaining } & \multirow{2}{*}{$\begin{array}{l}\text { No. of positive } \\
\text { cases (\%) }\end{array}$} \\
\hline & & $3+$ & $2+$ & $1+$ & 0 & & $3+$ & $2+$ & $1+$ & 0 & \\
\hline SCC & 38 & 1 & 2 & 3 & 32 & 6/38 (15.8) & 12 & 13 & 11 & 2 & $36 / 38(94.7)$ \\
\hline PA & 3 & 0 & 0 & 0 & 3 & $0 / 3(0)$ & 0 & 0 & 1 & 2 & $1 / 3(33.3)$ \\
\hline MPA & 3 & 0 & 0 & 0 & 3 & $0 / 3(0)$ & 0 & 0 & 2 & 1 & $2 / 3(66.7)$ \\
\hline $\mathrm{ACC}$ & 2 & 0 & 0 & 0 & 2 & $0 / 2(0)$ & 0 & 0 & 1 & 1 & $1 / 2(50)$ \\
\hline $\mathrm{MC}$ & 1 & 0 & 0 & 0 & 1 & $0 / 1(0)$ & 0 & 0 & 0 & 1 & $0 / 1(0)$ \\
\hline $\mathrm{AL}$ & 1 & 0 & 0 & 0 & 1 & $0 / 1(0)$ & 0 & 0 & 1 & 0 & $1 / 1(100)$ \\
\hline
\end{tabular}




\section{Acknowledgments}

The authors thank Takuro Nakamura, Miyuki Yanaka, Noriko Saidoh, Saori Handa, and Yoshimi Nakamura for excellent technical assistance. This work was mainly supported by the Basic Science and Platform Technology Program for Innovative Biological Medicine from Japan Agency for Medical Research and Development [AMED] (Y.K.). This work was also supported, in part, by Platform Project for Supporting Drug Discovery and Life Science Research [Basis for Supporting Innovative Drug Discovery and Life Science Research (BINDS)] from AMED (Y.K.) and by Project for utilizing glycans in the development of innovative drug discovery technologies from AMED (Y.K.).

\section{Author Disclosure Statement}

Y.K. received research funding from Ono Pharmaceutical Co., Ltd.

\section{References}

1. Dokala A, and Thakur SS: Extracellular region of epidermal growth factor receptor: A potential target for antiEGFR drug discovery. Oncogene 2017;36:2337-2344.

2. Ogiso H, Ishitani R, Nureki O, Fukai S, Yamanaka M, Kim JH, Saito K, Sakamoto A, Inoue M, Shirouzu M, and Yokoyama S: Crystal structure of the complex of human epidermal growth factor and receptor extracellular domains. Cell 2002;110:775-787.

3. Downward J, Yarden Y, Mayes E, Scrace G, Totty N, Stockwell P, Ullrich A, Schlessinger J, and Waterfield MD: Close similarity of epidermal growth factor receptor and v-erb-B oncogene protein sequences. Nature 1984;307: 521-527.

4. Yu X, Wang L, Shen Y, Wang C, Zhang Y, Meng Y, Yang Y, Liang B, Zhou B, Wang H, Wei H, Lei C, Hu S, and Li B: Targeting EGFR/HER2 heterodimerization with a novel anti-HER2 domain II/III antibody. Mol Immunol 2017;87: 300-307.

5. Littlefield P, Liu L, Mysore V, Shan Y, Shaw DE, and Jura $\mathrm{N}$ : Structural analysis of the EGFR/HER3 heterodimer reveals the molecular basis for activating HER3 mutations. Sci Signal 2014;7:ra114.

6. Khazaie K, Dull TJ, Graf T, Schlessinger J, Ullrich A, Beug $\mathrm{H}$, and Vennstrom B: Truncation of the human EGF receptor leads to differential transforming potentials in primary avian fibroblasts and erythroblasts. EMBO J 1988;7:30613071.

7. Mendelsohn J: The epidermal growth factor receptor as a target for cancer therapy. Endocr Relat Cancer 2001;8:3-9.

8. Mendelsohn J, and Baselga J: The EGF receptor family as targets for cancer therapy. Oncogene 2000;19:6550-6565.

9. Greillier L, Tomasini P, and Barlesi F: Necitumumab for non-small cell lung cancer. Expert Opin Biol Ther 2015; 15:1231-1239.

10. Uchibori K, Inase N, Araki M, Kamada M, Sato S, Okuno Y, Fujita N, and Katayama R: Brigatinib combined with anti-EGFR antibody overcomes osimertinib resistance in EGFR-mutated non-small-cell lung cancer. Nat Commun 2017;8:14768.

11. Itai S, Fujii $Y$, Kaneko MK, Yamada S, Nakamura $T$, Yanaka M, Saidoh N, Chang YW, Handa S, Takahashi M, Suzuki H, Harada $\mathrm{H}$, and Kato $\mathrm{Y}: \mathrm{H}_{2} \mathrm{Mab}-77$ is a sensitive and specific anti-HER2 monoclonal antibody against breast cancer. Monoclon Antib Immunodiagn Immunother 2017;36: 143-148.

12. Fujii Y, Kaneko MK, and Kato Y: MAP Tag: A novel tagging system for protein purification and detection. Monoclon Antib Immunodiagn Immunother 2016;35:293-299.

13. Fujii Y, Kaneko M, Neyazaki M, Nogi T, Kato Y, and Takagi J: PA tag: A versatile protein tagging system using a super high affinity antibody against a dodecapeptide derived from human podoplanin. Protein Expr Purif 2014; 95:240-247.

14. Fujii Y, Kaneko MK, Ogasawara S, Yamada S, Yanaka M, Nakamura T, Saidoh N, Yoshida K, Honma R, and Kato Y: Development of RAP tag, a novel tagging system for protein detection and purification. Monoclon Antib Immunodiagn Immunother 2017;36:68-71.

15. Kato Y, Fujita N, Kunita A, Sato S, Kaneko M, Osawa M, and Tsuruo T: Molecular identification of Aggrus/T1alpha as a platelet aggregation-inducing factor expressed in colorectal tumors. J Biol Chem 2003;278:51599-51605.

16. Kato Y, and Kaneko MK: A cancer-specific monoclonal antibody recognizes the aberrantly glycosylated podoplanin. Sci Rep 2014;4:5924.

17. Kaneko MK, Yamada S, Nakamura T, Abe S, Nishioka Y, Kunita A, Fukayama M, Fujii Y, Ogasawara S, and Kato Y: Antitumor activity of chLpMab-2, a human-mouse chimeric cancer-specific antihuman podoplanin antibody, via antibody-dependent cellular cytotoxicity. Cancer Med 2017; 6:768-777.

18. Yamada S, Ogasawara S, Kaneko MK, and Kato Y: LpMab-23: A cancer-specific monoclonal antibody against human podoplanin. Monoclon Antib Immunodiagn Immunother 2017;36:72-76.

19. Kaneko MK, Nakamura T, Kunita A, Fukayama M, Abe S, Nishioka Y, Yamada S, Yanaka M, Saidoh N, Yoshida K, Fujii Y, Ogasawara S, and Kato Y: ChLpMab-23: Cancerspecific human-mouse chimeric anti-podoplanin antibody exhibits antitumor activity via antibody-dependent cellular cytotoxicity. Monoclon Antib Immunodiagn Immunother 2017. DOI:10.1089/mab.2017.0014.

20. Ogasawara S, Kaneko MK, Yamada S, Honma R, Nakamura T, Saidoh N, Yanaka M, Yoshida K, Fujii Y, and Kato Y: PcMab-47: Novel antihuman podocalyxin monoclonal antibody for immunohistochemistry. Monoclon Antib Immunodiagn Immunother 2017;36:50-56.

21. Wang S, Guo P, Wang X, Zhou Q, and Gallo JM: Preclinical pharmacokinetic/pharmacodynamic models of gefitinib and the design of equivalent dosing regimens in EGFR wild-type and mutant tumor models. Mol Cancer Ther 2008;7:407-417.

22. Demiroglu-Zergeroglu A, Candemir G, Turhanlar E, Sagir F, and Ayvali N: EGFR-dependent signalling reduced and p38 dependent apoptosis required by Gallic acid in Malignant Mesothelioma cells. Biomed Pharmacother 2016;84: 2000-2007.

23. King IC, and Sartorelli AC: The relationship between epidermal growth factor receptors and the terminal differentiation of A431 carcinoma cells. Biochem Biophys Res Commun 1986;140:837-843.

24. Oki H, Ogasawara S, Kaneko MK, Takagi M, Yamauchi M, and Kato Y: Characterization of monoclonal antibody LpMab-3 recognizing sialylated glycopeptide of podoplanin. Monoclon Antib Immunodiagn Immunother 2015;34: 44-50. 
25. Kato Y, Ogasawara S, Oki H, Goichberg P, Honma R, Fujii Y, and Kaneko MK: LpMab-12 established by CasMab technology specifically detects sialylated O-glycan on Thr52 of platelet aggregation-stimulating domain of human podoplanin. PLoS One 2016;11:e0152912.

26. Ogasawara S, Kaneko MK, and Kato Y: LpMab-19 Recognizes sialylated O-glycan on Thr76 of human podoplanin. Monoclon Antib Immunodiagn Immunother 2016.

27. Kaneko MK, Nakamura T, Honma R, Ogasawara S, Fujii Y, Abe S, Takagi M, Harada H, Suzuki H, Nishioka Y, and Kato Y: Development and characterization of anti-glycopeptide monoclonal antibodies against human podoplanin, using glycan-deficient cell lines generated by CRISPR/Cas9 and TALEN. Cancer Med 2017;6:382-396.

28. Kato Y, Kunita A, Fukayama M, Abe S, Nishioka Y, Uchida H, Tahara H, Yamada S, Yanaka M, Nakamura T, Saidoh N, Yoshida K, Fujii Y, Honma R, Takagi M, Ogasawara S, Murata T, and Kaneko MK: Antiglycopeptide mouse monoclonal antibody LpMab-21 exerts antitumor activity against human podoplanin through antibodydependent cellular cytotoxicity and complement-dependent cytotoxicity. Monoclon Antib Immunodiagn Immunother 2017;36:20-24.

29. Yamada S, Kaneko MK, Nakamura T, Ichii O, Konnai S, and Kato Y: Development of mPMab-1, a mouse-rat chi- meric antibody against mouse podoplanin. Monoclon Antib Immunodiagn Immunother 2017;36:77-79.

30. Kato Y, Kunita A, Abe S, Ogasawara S, Fujii Y, Oki H, Fukayama M, Nishioka Y, and Kaneko MK: The chimeric antibody chLpMab-7 targeting human podoplanin suppresses pulmonary metastasis via ADCC and CDC rather than via its neutralizing activity. Oncotarget 2015;6:36003-36018.

Address correspondence to: Yukinari Kato New Industry Creation Hatchery Center Tohoku University Department of Antibody Drug Development Tohoku University Graduate School of Medicine 2-1 Seiryo-machi Aoba-ku Sendai Miyagi 980-8575 Japan

E-mail: yukinari-k@bea.hi-ho.ne.jp; yukinarikato@med.tohoku.ac.jp

Received: August 8, 2017 Accepted: September 30, 2017 